\title{
Total nitrogen removal of synthetic leather wastewater treated by MBBR
} Yuanhong Ding ${ }^{1, a}$, Yi Qian ${ }^{1}$, Lingling $\mathrm{Li}^{1}{ }^{1}$,Hongqiang Ren $^{2 *}$, Qing Wang ${ }^{2}$

${ }^{1}$ School of environment, Qingdao University of Science and Technology, Qingdao, 266000 China. ${ }^{2}$ State key Lab. of pollution control and resources reuse, Nanjing University, Nanjing, 210093 China aemail: yhding@nju.edu.cn

Keywords: synthetic leather wastewater; MBBR; total nitrogen; nitrate nitrogen.

\begin{abstract}
Moving Bed Bio-film Reactor combined with membrane (MBBR) was used to treat a kind of synthetic leather wastewater, when the value of BOD/TN was controlled from 0.8 to 1.5 , about $83.6 \%$ of ammonia nitrogen, $61.5 \%$ of total nitrogen, $87.4 \%$ of nitrate nitrogen, was averagely removed respectively, when the concentrations of total nitrogen, ammonia nitrogen, or nitrate nitrogen was maintained about below $200 \mathrm{mg} / \mathrm{L}$, its removal efficiencies were increased gradually. The results indicated that, the A /O MBBR combined with membrane, could be used to remove ammonia, nitrate or TN nitrogen off synthetic wastewater effectively, and a much more lower value of $\mathrm{C} / \mathrm{N}$ in anoxic $\mathrm{MBBR}$ was needed than that in other conventional anoxic biological denitrifying facilities.
\end{abstract}

\section{Introduction}

There are more than 2,000 synthetic leather factories in china, discharging off 10,000 thousands tons of wastewater per year, N,N-Dimethylformamide (DMF), as a kind of excellent solvents, is used to treat with the surface modification of synthetic leather, and usually found in the synthetic leather wastewater that is toxic and inhibitive to bacteria's activities[1,2], many physic-chemical or biological processes, such as extraction, sequencing batch reactor, integrated anoxic-aerobic biochemical process and etc, were applied to the treatment of synthetic leather wastewater [3], in which process COD (chemical oxygen demand), SS (suspended solid), $\mathrm{Cr}$ and sulfide were removed off effectively, however, the discharged concentration of ammonia nitrogen or total nitrogen $(\mathrm{TN})$ hardly reached the national wastewater disposal standard $[4,5]$, this phenomena could be explained that, one of components degraded from DMF is ammonia nitrogen, both DMF and high-strength ammonia nitrogen are inhibitive to the activities of microorganism enzyme, that results probably in the decrease of nitrogen removal efficiencies, another cause may be that, low effective anoxic denitrification did result in the accumulations of nitrate nitrogen. Since 2008, the demand for residual ammonia nitrogen and total nitrogen in effluent is much more stricter than ever before in new " Pollutants Disposal Standard of Synthetic Leather Industrial Wastewater (PDSSLIW) GB 21902-2008", therefore it is urgent to update present synthetic leather wastewater treatment facilities to achieve deep nitrogen removal.

Moving-Bed Biofilm Reactor (MBBR), composed of moving carriers attached on lots of microorganism, is regarded as a kind of effectively biological method to treat refractory organic industrial wastewater[6], in which the microorganism attached on carrier does not fall off easily, contacts and degrades with pollutants completely. Membrane Bioreactors (MBR) is another kind of useful biological reactor to treat refractory organic industrial wastewater with optional long sludge retention time, in which the microorganism is captured completely in biological reactor by membrane and degraded pollutants with enough microorganism amount and reacting time. As the synthetic leather wastewater, containing with DMF and high-strength ammonia nitrogen, could be regarded as a kind of refractory organic wastewater, therefore, an anoxic-aerobic MBBR reactor combined with membrane, could be applied with its treatment reasonably[7].

In common, if ammonia nitrogen concentration was below $50 \mathrm{mg} / \mathrm{L}$, it could be treated easily by activated sludge process, however, when that was higher than $150 \mathrm{mg} / \mathrm{L}$, it could hardly be done very well, In this experiments, two anoxic-aerobic MBBR reactor combined with membrane, was set up, and used to treat with raw wastewater and effluent treated before, which ammonia, nitrate, or 
TN concentration was controlled about between 150 and $300 \mathrm{mg} / \mathrm{L}$, and this investigation mainly focuses on the removal efficiencies of nitrogen compounds in synthetic leather wastewater.

\section{Materials and Method}

\section{The Experimental Series}

This experimental setup, named as combined anoxic-aerobic MBBR, was used to investigate on the removal effects of ammonia nitrogen, total nitrogen ,nitrate nitrogen and COD in synthetic leather wastewater, There were 3 series of MBBR reactors, made of organic glass, with length of $220 \mathrm{~mm}$, breadth of $200 \mathrm{~mm}$ and height of $500 \mathrm{~mm}$, the carriers of MBBR was made of polyethylene materials, seemed like hollow cylinder, with height of $7 \mathrm{~mm}$ and diameter of $10 \mathrm{~mm}$, its specific surface area was about $500 \mathrm{~m}^{2} / \mathrm{m}^{3}$, the rate of carrier's filling in MBBR was about 40 percentage, and its tumbling force was supplied by an electric blender.

There were 3 pieces of plate membrane, assembled in the discharging chamber of aerobic MBBR, which chamber was made with metal mesh, the membrane was with breadth of $220 \mathrm{~mm}$ and height of $400 \mathrm{~mm}$, the plate membrane was supplied by Jiangsu Dafu Membrane Co.Ltd, its available area was about $0.18 \mathrm{~m}^{2}$ its pore size was $0.1 \sim 0.4 \mu \mathrm{m}$, its maximum flux was $0.2 \mathrm{~m}^{3} /\left(\mathrm{m}^{2} . \mathrm{d}\right)$, the flux was intermediately suck from membranes by a peristaltic pump, its MLSS (Mixed Liquor Suspended Sludge) about $3.0 \sim 10.0 \mathrm{~g} / \mathrm{L}$, the activated sludge was brought from the denitrifying and nitrifying process of Jiangsu Yixing Qingyuan Municipal Wastewater Treatment Plant. The wastewater, sampled from Hangzhou Xingye Synthetic Leather Co. Ltd., was pumped into anoxic MBBR reactors for anoxic hydrolysis-acidification and denitrification reaction, then its effluents was flown by gravity into aerobic part for aerobic nitrification reaction continuously.

\section{Synthetic Leather Wastewater}

The quality of raw water was about COD of $59.35 \sim 416 \mathrm{mg} / \mathrm{L}$, ammonia nitrogen of $48.5 \sim$ $311.74 \mathrm{mg} / \mathrm{L}$, total nitrogen of $203.1 \sim 360.63 \mathrm{mg} / \mathrm{L}$.

\section{Analytical Methods}

The measurements of COD, ammonia nitrogen, nitrate nitrogen, total nitrogen, and total organic carbon (TOC) was conducted according to the Standard Methods, spectrophotometer UV2500 (Shimadzu) and TOC-5000 (Shimadzu) analyzer were applied.

\section{Results and discussions}

\section{The removal effect on ammonia by combined A/O MBBR}

As we know, ammonia nitrogen could be converted to nitrite or nitrate nitrogen in aerobic process, which could continuously be converted to nitrogen gas in anoxic condition, in Fig 1, the removal efficiencies of ammonia nitrogen in anoxic MBBR, aerobic MBBR and combined MBBR, was averagely $54.6 \%, 62.6 \%$ and $83.6 \%$ respectively, when concentration of ammonia nitrogen in influent was higher than $250 \mathrm{mg} / \mathrm{L}$, its removal efficiencies was lower than $60 \%$ because of an inhibition to the bacteria activities by high-concentration ammonia nitrogen, however, when concentration of ammonia nitrogen in influent was maintained lower than $200 \mathrm{mg} / \mathrm{L}$, the ammonia concentration of effluent could be maintained below $3.9 \mathrm{mg} / \mathrm{L}$ averagely. The results indicated that, ammonia nitrogen could be removed well off synthetic leather wastewater by a combined A /O MBBR, although there was an inhibition to bacteria activities by high-concentration ammonia nitrogen. 

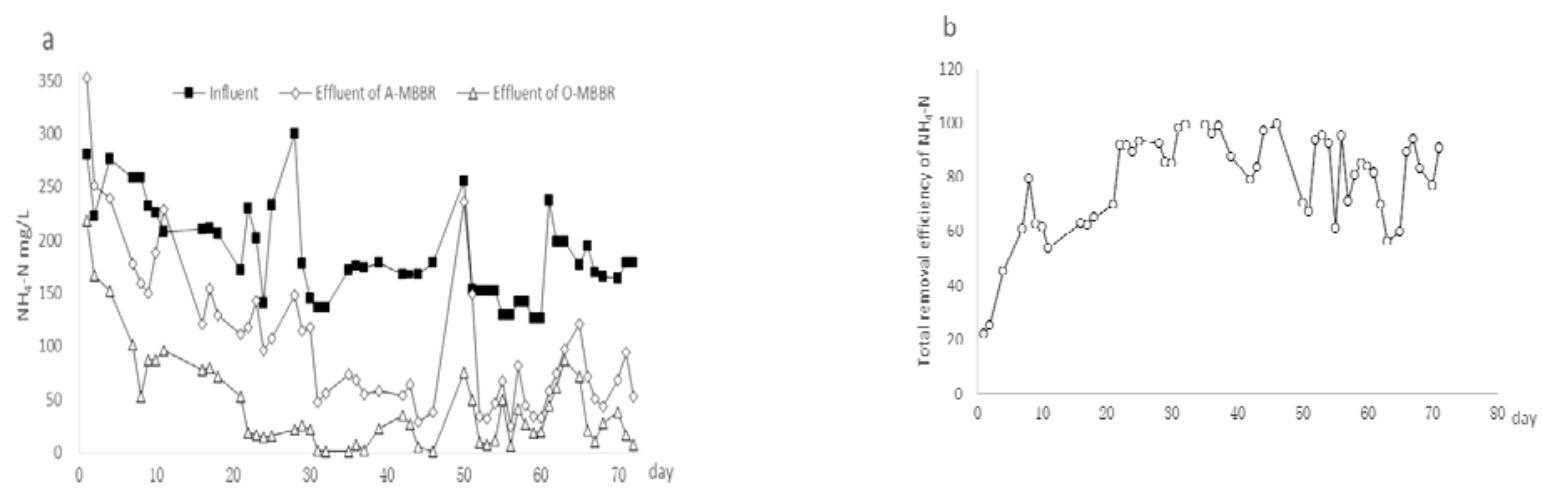

Fig. 1. The removal efficiency of ammonia by combined A/O MBBR

The value DHA (dehydrogenase activity) of biofilm scaled off MBBR carriers, was analyzed, and it was $78.436 \mu \mathrm{g} \mathrm{TF} /(\mathrm{mg} \cdot \mathrm{h})$ averagely, much more higher than that of activated sludge, it could explain why ammonia nitrogen could degraded well by MBBR reactor.

\section{The removal effect on total nitrogen by combined A/O MBBR}
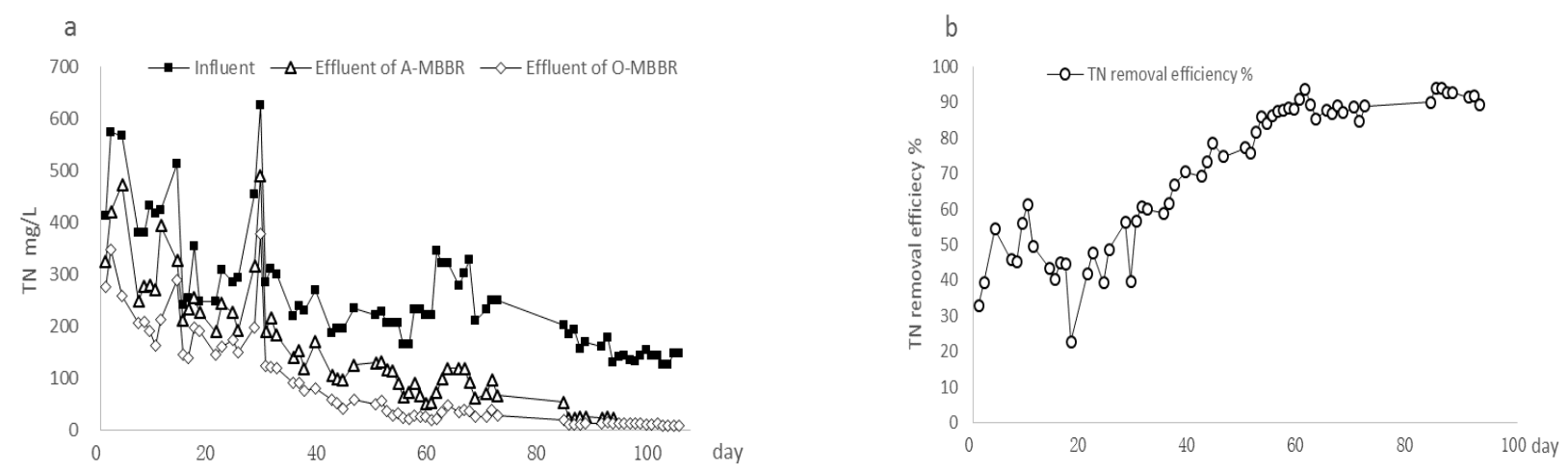

Fig. 2. The removal efficiency of total nitrogen by combined A/O MBBR

The concentration of total nitrogen in raw wastewater was from $126 \mathrm{mg} / \mathrm{L}$ to $626 \mathrm{mg} / \mathrm{L}$, when it was maintained about $200 \mathrm{mg} / \mathrm{L}$, as shown in Fig 2, the removal efficiency of total nitrogen was increased up to $97.5 \%$, the result indicated that, when concentration of total nitrogen was maintained at lower than $200 \mathrm{mg} / \mathrm{L}$, the denitrifying bacteria attached on the carriers in MBBR, had an excellent capacity to convert nitrate nitrogen to nitrogen gas, total nitrogen was mainly removed off at the stage of A-MBBR reactor, on the whole, the combined A/O MBBR performed excellent removal effects on total nitrogen in raw synthetic leather wastewater, however, when TN concentration was maintained from $300 \mathrm{mg} / \mathrm{L}$ to $600 \mathrm{mg} / \mathrm{L}$, a removal efficiency of total nitrogen of $40 \%$ to $61.5 \%$ was still achieved.

The removal effect on nitrate nitrogen by combined A/O MBBR
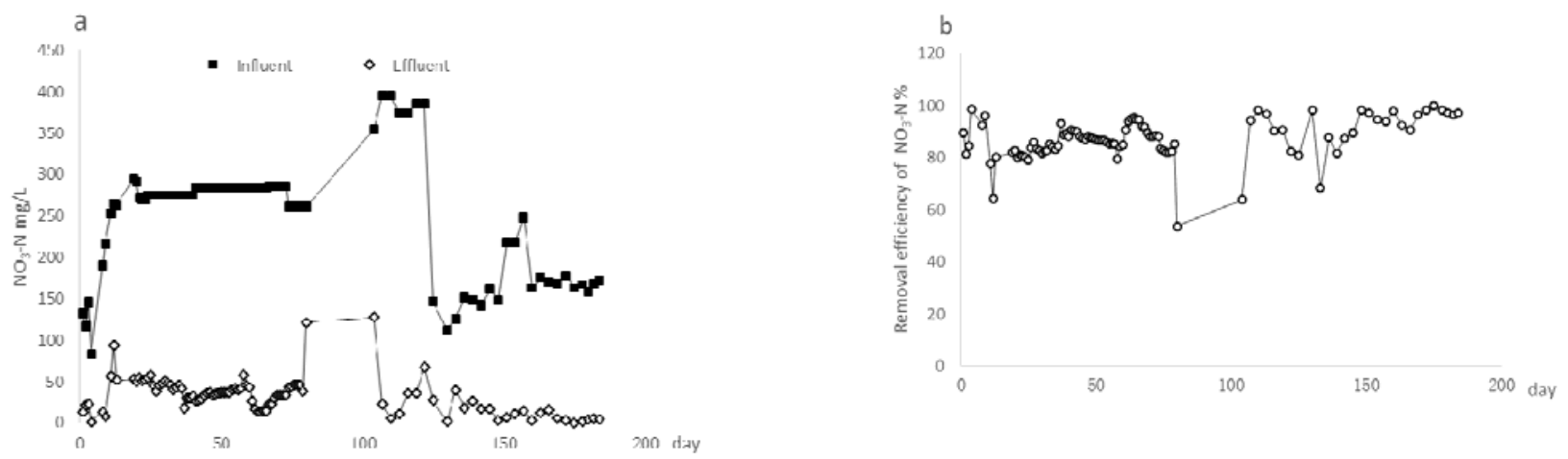

Fig .3. The removal effect on nitrate nitrogen by combined A/O MBBR

The wastewater in this experiment, was from the effluent of original bio-chemical treatment 
plant, and its total nitrogen was mainly composed of nitrate nitrogen, the water quality was characterized by high concentration level of nitrate nitrogen, in this experiment, $1 \mathrm{~L}$ of effluent mentioned above, was sampled and analyzed in details, and the value of COD, TOC (total organic carbon), nitrite nitrogen, ammonia, nitrate nitrogen, total nitrogen and chloride ion was $23.7 \mathrm{mg} / \mathrm{L}$, $5.13 \mathrm{mg} / \mathrm{L}, 0.064 \mathrm{mg} / \mathrm{L}, 0.74 \mathrm{mg} / \mathrm{L}, 334.0 \mathrm{mg} / \mathrm{L}, 335.6 \mathrm{mg} / \mathrm{L}$ and $32.5 \mathrm{mg} / \mathrm{L}$ respectively, the analytical results indicated that, some regular items, such as COD and ammonia of effluent could reach to standard PDSSLIW GB 21902-2008 except of total nitrogen, and total nitrogen was mainly composed of nitrate nitrogen, therefore, it need a way to remove nitrate or ammonia nitrogen effectively. As shown in Fig 3, about $87.4 \%$ of nitrate nitrogen was removed off by combined A /O MBBR, which showed that anoxic denitrifying bacteria attached on carrier of MBBR had an high capacity to denitrify nitrate nitrogen into nitrogen gas.

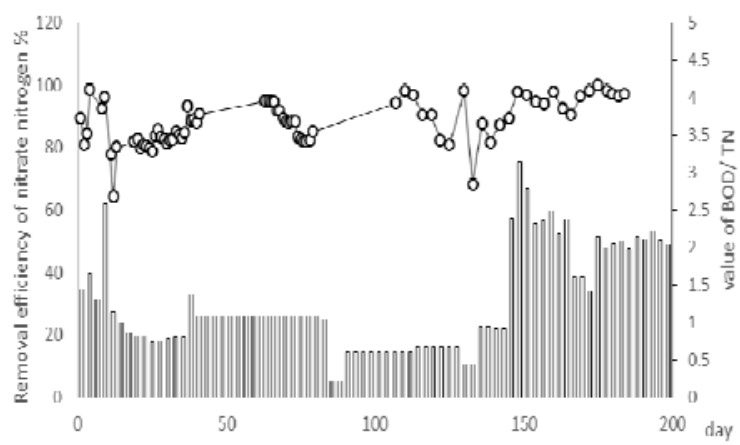

Fig. 4. The removal effect on nitrate nitrogen by combined A/O MBBR

In theory, the main component of total nitrogen in effluent from anoxic-aerobic biological process, was mainly nitrate nitrogen, if the concentration level of total nitrogen was about $50 \mathrm{mg} / \mathrm{L}$, it could be treated easily by bio-chemical process, such as a conventional activated sludge process, however, when concentration of total nitrogen was higher than $100 \mathrm{mg} / \mathrm{L}$, it could hardly be done very well, at present, there were many kinds of physical-chemical and bio-chemical ways to treat it effectively, such as $\mathrm{Fe}-\mathrm{Mg}$ reduction, ion exchange, reverse osmosis, electrodialysis and denitrification, however the physical-chemical ways had some disadvantage, such as high cost, secondary pollution and strict operation control, therefore this experimental results indicated that, the A /O MBBR had a potential capacity to removed $200 \sim 400 \mathrm{mg} / \mathrm{L}$ of nitrate nitrogen or total nitrogen off wastewater with environment harmony.

In common, external carbon resource was needed to be added into the anoxic biological process, in this experiment, glucose and sodium acetate was added into the anoxic MBBR reactor, Fig. 4 showed that, when the value of $\mathrm{BOD} / \mathrm{TN}$ was controlled from 0.8 to 1.5 , about 1.3 averagely, then a nitrate nitrogen removal efficiency of $88.2 \%$ at average, was observed, the result showed that, the value of $\mathrm{BOD} / \mathrm{TN}$ of effluent in anoxic MBBR was much more lower than that in conventional anoxic biological denitrifying facilities.

\section{Conclusions}

When the value of BOD/TN was controlled from 0.8 to 1.5 , about 1.3 averagely, about $83.6 \%$ of ammonia nitrogen, $61.5 \%$ of total nitrogen, $87.4 \%$ of nitrate nitrogen, was averagely removed respectively, this results indicated that, a much more lower value of BOD/TN in anoxic MBBR was needed than that in other conventional anoxic biological denitrifying facilities, when the concentration of $\mathrm{TN}$, ammonia nitrogen, or nitrate nitrogen was kept about below $200 \mathrm{mg} / \mathrm{L}$, all of its removal efficiencies increased gradually higher than $90 \%$, in details, most COD and ammonia nitrogen was removed in aerobic MBR, while most nitrate nitrogen and total nitrogen was removed in anoxic MBBR. Therefore, the results indicated that, the combined A/O MBBR could be used to remove ammonia, nitrate or total nitrogen off synthetic wastewater effectively, under the concentration level of $150 \sim 300 \mathrm{mg} / \mathrm{L}$, because the biofilm attached on the carriers in MBBR had 
some excellent resistance to inhibition of biological activity by high-concentration of ammonia nitrogen, nitrate nitrogen, DMF, or other refractory organic compounds in synthetic leather wastewater. On the other hand, all the microorganism was captured by membrane completely within the reactor, which was favorable to microorganism growth and bio-degradation to all kinds of pollutants in wastewater.

\section{Acknowledgement}

Authors wish to thank the Foundation of Jiangsu Science and Technology Project (2012011) to support the research, focusing on deep nitrogen removal of synthetic leather wastewater.

\section{References}

[1] Mannucci A, Munz G, Mori G, Lubello C. Anoxic treatment of vegetable tannery wastewaters: a review. Desalination 2010;264:1 - 8 .

[2] Qi Zhang, Rong Xu, Pengwei Xu, Ruoyu Chen, Qiang He, Jing Zhong, Xuehong Gu. Performance study of $\mathrm{ZrO} 2$ ceramic micro-filtration membranes used in pretreatment of DMF wastewater. Desalination 346 (2014) 1 - 8.

[3] Tamal Mandala, Dalia Dasgupta, Subhasis Mandal, Siddharth Datta. Treatment of leather industry wastewater by aerobic biological and Fenton oxidation process Journal of Hazardous Materials 180 (2010) $204-211$.

[4] Giusy Lofrano, Sureyya Meriç, Gülsüm Emel Zengin, Derin Orhon. Chemical and biological treatment technologies for leather tannery.chemicals and wastewaters: A review.Science of the Total Environment 461 - 462 (2013) 265 - 281

[5] Romero Dondiz, E.M., et al., Removal of vegetable tannins to recover water in the leather industry by ultrafiltration polymeric membranes. Chem. Eng. Res. Des. (2014), http://dx.doi.org/10.1016/j.cherd.2014.06.022

[6] S. Yang, F. Yang, Z. Fu, R. Lei, Comparison between a moving bed membrane bioreactor and a conventional membrane bioreactor on organic carbon and nitrogen removal, Bioresour. Technol. 100 (2009) $2369-2374$.

[7] J.C. Leyva-Diaz, A. Gonzalez-Martinez, J. Gonzalez-Lopez, M.M. Munio. kinetic modeling and microbiological study of two-step nitrification in a membrane bioreactor and hybrid moving bed biofilm reactor - membrane bioreactor for wastewater treatment. Chemical Engineering Journal 259 (2015) $692-702$ 